\title{
A SIMPLE METHOD FOR DETERMINING VAPOR DENSITIES
}

\section{BY PHILIP BLACKMAN}

\section{PART IX ${ }^{1}$}

The two equations given in the Journal of Physical Chemistry, 12, 670 (1908), can be converted into the single simple equation given on page 676 (Ibid.) in the following manner. $^{2}$ On page 670 replace $w_{1}, w_{2}$, throughout by $x_{1}$, $x_{2}$, respectively; then the respective equations become

and $x_{1}+x_{2}=w$.

$$
d_{1} x_{2}+d_{2} x_{1}=\frac{d_{1} d_{2} p \mathrm{IV}\left(\mathrm{L}_{c}-l\right)}{31068 l \mathrm{~L}_{c}\left(273+t_{1}\right)},
$$

Since $x_{2}=w-x_{1}$, the first equation may be written

$$
d_{1}\left(w-x_{1}\right)+d_{2} x_{1}=\frac{d_{1} d_{2} p L V\left(L_{c}-l\right)}{3 \operatorname{Io6} l L_{1 c}\left(273+t_{1}\right)},
$$

which, on multiplication throughout by the factor $100 / w$, becomes

$$
d_{1}\left(100-\frac{\operatorname{100x}}{w}\right)+d_{2}\left(\frac{\operatorname{100x} x_{1}}{w}\right)=\frac{\operatorname{I00} d_{1} d_{2} p L V\left(L_{c}-l\right)}{3 \operatorname{I068} w l L_{1}\left(273+t_{1}\right)} .
$$

But $\left(100 x_{1} / w\right)$ represents the percentage by weight of the component $x_{1}$ and let it be written $w_{1}$; and (IOO- $\frac{\operatorname{IOO} x_{1}}{w}$ ) that of the second constituent, which is now equal to $w_{2}$ or Ioo $-w_{1}$, therefore

$$
d_{1}\left(100-w_{1}\right)+d_{2} w_{1}=\frac{100 d_{1} d_{2} p L V\left(L_{c}-l\right)}{31068 v l L_{c}\left(273-\frac{t_{1}}{2}\right)} .
$$

There is not the slightest need for using thick-walled or Jena tubing from which to make the bulb; any kind of tubing (of not too thin walls) will do perfectly well, and is moreover very easy to seal up or open. The author invariably

\footnotetext{
${ }^{1}$ Continued from Jour. Phys. Chem., I3, I43 (Igog).

${ }^{2}$ Cf. Zeit. phys. Chem., 65, 550 (1909).
} 
used ordinary glass tubing of wall-thickness not exceeding I. $5 \mathrm{~mm}$.

It has already been pointed out that there is not the slightest need for using a graduated capillary tube for manometer, as $\mathrm{L}, \mathrm{L}_{c}$, and $l$ can very easily be measured by the aid of a $\mathrm{mm}$ measure, compass, dividers, or callipers. However, should anyone still desire to use a graduated tube, there is no necessity whatever to go to the trouble of making one, as the graduated stem of a disused thermometer will do quite well for the purpose. It is quite immaterial whether $\mathrm{L}, \mathrm{L}_{c}$, and $l$ are measured in $\mathrm{mm}$, inches, or any other unit of length (provided one unit only is used throughout); this will be at once evident from the formula

where the factor

$$
\frac{3 \operatorname{IO} 68 w l \mathrm{~L}_{c}\left(273+t_{1}\right)}{\operatorname{pIV}\left(\mathrm{L}_{c}-1\right)}
$$

$$
\frac{l \mathrm{~L}_{c}}{\mathrm{~L}\left(\mathrm{~L}_{c}-l\right)}
$$

plainly from its nature is simply a numerical quantity.

It is the author's opinion that in the special apparatus described and figured on page 678 a hollow stopper would much better withstand heat than a solid one.
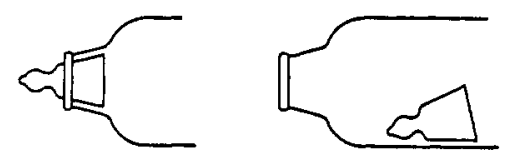

Fig. I

The following is a brief, clear summary of the essential consecutive steps in the performance of an experiment. A clean tube has one end closed. The manometer is prepared, cooled down to room temperature, and $\mathrm{L}$ measured. The manometer and weighed quantity $w$ of substance to be experimented on are introduced into the tube. The tube is now sealed, allowed to cool to room temperature, and $\mathrm{L}_{c}$ measured. The room temperature $t_{1}$ and atmospheric pressure $p$ are determined. The apparatus is next heated to 
$t_{2}$ and $l$ measured. The bulb is finally opened and $\mathrm{V}$ determined, and the necessary calculations effected.

Interesting variations for the method of obtaining the necessary formula for calculating vapor-density will be found in the Chemical News, 99, 87 (I909).

\section{PART $X$ \\ Preparation of Manometer}

The methods here described for preparing the pressuregauge or manometer will be found much easier and more convenient than that previously detailed by the author, and they possess the additional advantages that the mercurythread can be placed in any desired position and may be made of any required length.

(I) If the bore of the capillary-tube be very narrow, a piece of rubber tubing is pushed over one end, and a thread of mercury of required length is sucked in at the other end and drawn in till it reaches a convenient position near the rubberfastened end, when the rubber tubing is immediately closed with a clip or pinchcock; the other end of the capillary-tube is sealed off in the flame, and the rubber-tube opened and finally removed.

(2) If the bore of the capillary-tube is not too narrow, one end of the tube is sealed off. A piece of glass tubing is softened in the flame and drawn out to a long, straight, fine (narrow) capillary-tube (see Fig. 2). This is filled with a drop of mercury, inserted in a horizontal position into the capillary-tube until its end reaches the desired position within the bore, and by gently raising the two tubes into an upright or a semivertical position a thread of mercury of the required length will run into the capillary-tube, after which the Fig. 2 filling-tube is taken out.

\section{New Apparatus for Liquids}

A capillary-tube, 30 to $40 \mathrm{~cm}$ long (the longer the better) with not too narrow a bore has one end sealed up and a mercury-thread inserted somewhere near the middle of it as is 
described under "Method 2" above. A short thread (3 to $5 \mathrm{~mm}$ in length) of the liquid whose vapor-density is to be determined is put into the bore 3 or $4 \mathrm{~cm}$ away from the mercury-thread. The length $I$ of the air-thread enclosed between the mercury-thread and the sealed end is measured, and also the length $\delta$ of the thread of liquid is determined (see Fig. 3). By the aid of an ordinary magnifying-glass it should be possible to measure $\delta$ to fourths or even fifths of a $\mathrm{mm}$. The other, open end of the tube is now sealed off, and when it has had time to cool down to room temperature the length $L_{c}$ of the manometric air-thread ( $i$. e., between the mercury-thread and the sealed end on its side) is measured (see Fig. 4).

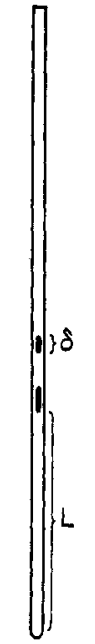

Fig. 3

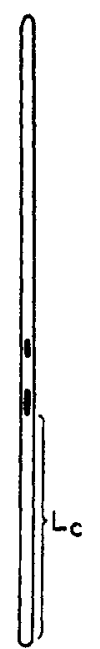

Fig. 4

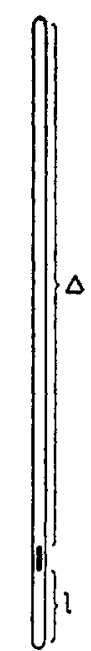

Fig. 5

The tube is heated to a temperature sufficiently high to vaporize completely the enclosed substance (either by means of a heating-jacket and the vapor from a suitable boiling liquid, or better in a thermostat containing a heating-medium such as glycerin or paraffin-wax). The vaporizing-temperature will generally have to be very high, much higher than the temperature at which the substance vaporizes at ordinary atmospheric pressures, because the pressures within the 
capillary-tube are very great. For this same reason, any liquid which decomposes at high temperatures cannot be experimented upon with this apparatus. When the mercury-thread has become stationary the length $l$ of the manometric air-thread is measured, and also the length $\delta$ of the bore of the capillary-tube occupied by the vapor of the substance is determined (see Fig. 5).

The room-temperature $t_{1}$ and the atmospheric pressure $p$ are measured.

(In very accurate work allowance must be made for the concavity of the ends of the substance when measuring $\delta$; the correction however is very small and may for all ordinary purposes be neglected).

The specific gravity $s$ (as measured on the metric-system) of the substance experimented upon must be determined at the temperature of the measurement of $\delta$.

Let $\alpha=$ the area of the cross-section of the bore of the capillary-tube ( $\alpha$ is not required to be known); then the weight of the substance $=s \delta \alpha$, and the volume of the vapor $=\Delta \alpha$; substituting these quantities for $w$ and $V$ respectively in the formula hitherto used, the formula to be employed in the calculation of vapor-densities with this apparatus is

$$
d=\frac{3 \mathrm{IO} 68 \operatorname{s} \delta l \mathrm{~L}_{c}\left(273+t_{1}\right)}{p \mathrm{~L} \Delta\left(\mathrm{L}_{i}-l\right)} .
$$

It will be noticed that with this apparatus consideration of $\mathrm{H}, n$, is entirely absent ${ }^{1}$ and thus the formula just quoted is quite correct.

The apparatus should not be used with substances which act upon mercury.

This method may not be found so accurate as the ones previously described by the author, but it is nevertheless exceedingly interesting both from practical and theoretical points of view.

When the tube is being finally sealed up, it will be found that the warmth from the hand and the heat from the sealed

'See Zeit. phys. Chem., 63, 49 ( go8). 
end are able to cause the enclosed air in the bore to exert a sufficiently great pressure to distend the bore at the softened, sealed end and very often to blow a hole through that part. The author could discover only one way of preventing this. The other sealed end is pushed into a cork, by which the tube is to be claniped while it is being sealed (see Fig. 6). When the softened end has closed in the flame, the tube, while still being held in the flame, is rubbed with a piece of filter-paper or blotting paper moistened with some volatile liquid; the cooling effect of this will generally repress the expansive force of the contained air, and enable the end to be well sealed off and annealed. This cooling process must be continued some little time after the tube has been removed from the flame, until the soft end has had time to solidify. These operations will be found the most difficult part of the experiment, and on it more than on any other will depend the success of a determination.

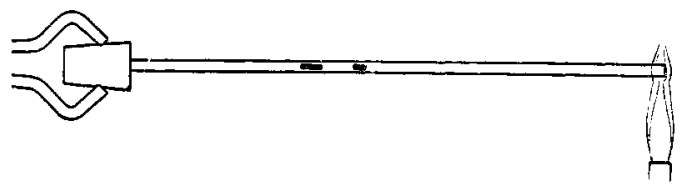

Fig. 6

The tube may be heated to $t_{2}^{\circ}$ in an upright (vertical) position if desired, for the internal pressure is so great that the weight of the mercury-thread is of negligible effect upon the column of air (see the observation upon this question in the Zeitschrift für physikalische Chemie, 63, 5I (1908)).

\begin{tabular}{|c|c|c|c|c|c|c|c|c|c|c|}
\hline \multirow{2}{*}{ Substance } & & \multirow{2}{*}{$\begin{array}{c}\delta \\
\mathrm{mm}\end{array}$} & \multirow{2}{*}{$\stackrel{l}{\mathrm{~mm}}$} & \multirow{2}{*}{$\stackrel{\mathrm{L}}{\mathrm{mm}}$} & \multirow{2}{*}{$\underset{\mathrm{mm}}{\mathrm{L}_{c}}$} & \multirow{2}{*}{$\underset{\mathrm{mm}}{p}$} & \multirow{2}{*}{$\begin{array}{l}t_{1} \\
{ }^{\circ} \mathrm{C}\end{array}$} & \multirow{2}{*}{$\begin{array}{c}\Delta \\
\mathrm{mm}\end{array}$} & \multicolumn{2}{|c|}{$d$} \\
\hline & & & & & & & & & Found & Theory \\
\hline $\begin{array}{l}\left(\mathrm{C}_{2} \mathrm{H}_{5}\right) \\
\mathrm{CO}(\mathrm{CI}\end{array}$ & 0.7996 & $\begin{array}{l}3.5 \\
2.25\end{array}$ & $\begin{array}{l}33 \\
4^{2}\end{array}$ & $\begin{array}{l}\text { I } 29 \\
\text { I } 3 \text { I }\end{array}$ & $\begin{array}{l}135 \\
147\end{array}$ & $\begin{array}{l}746 \\
75 \mathrm{I}\end{array}$ & $\begin{array}{l}I_{5} \\
\text { I } 4\end{array}$ & $\begin{array}{r}304 \\
298\end{array}$ & $\begin{array}{l}35 . I \\
32.6\end{array}$ & $\begin{array}{l}37.0 \\
29.0\end{array}$ \\
\hline
\end{tabular}

\section{Errata}

Page 66I. The footnote should refer not to the title, but only to Part I. Only Part I was read before the London Chem. Soc. 
Page 662, line $\mathrm{I} 4$; instead of "Hh" read " $\mathrm{H}$, h."

Page 670 , line $I$; instead of "let $w, w_{2}$ " read "let $w_{1}$, $w_{2}$ "

Page 670, line 5; instead of " or $=$ "read " or $\phi=$ ".

Page 6;2, line 30; instead of "need, whatever, to" read "need whatever to."

Hackney Technical Institute,

London, N. E. England. 